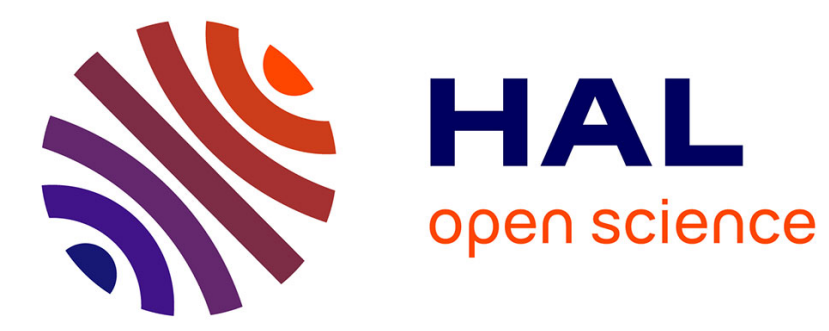

\title{
Micro-irradiation experiments in MOS transistors using synchrotron radiation
}

J. Autran, P. Masson, N. Freud, Christophe Raynaud, C. Riekel

\section{To cite this version:}

J. Autran, P. Masson, N. Freud, Christophe Raynaud, C. Riekel. Micro-irradiation experiments in MOS transistors using synchrotron radiation. IEEE Transactions on Nuclear Science, 2000, 47 (3 Part 1), pp.574-579. hal-00141515

\section{HAL Id: hal-00141515 https://hal.science/hal-00141515}

Submitted on 18 Apr 2007

HAL is a multi-disciplinary open access archive for the deposit and dissemination of scientific research documents, whether they are published or not. The documents may come from teaching and research institutions in France or abroad, or from public or private research centers.
L'archive ouverte pluridisciplinaire HAL, est destinée au dépôt et à la diffusion de documents scientifiques de niveau recherche, publiés ou non, émanant des établissements d'enseignement et de recherche français ou étrangers, des laboratoires publics ou privés. 
Micro-Irradiation Experiments in MOS Transistors Using Synchrotron Radiation ${ }^{\dagger}$

\author{
J.L. Autran ${ }^{1, *}$, Member, IEEE, P. Masson ${ }^{1-2}$, Member, IEEE, N. Freud ${ }^{3}$, \\ C. Raynaud ${ }^{1-4}$ and C. Riekel ${ }^{5}$ \\ ${ }^{1}$ LPM, UMR CNRS 5511, INSA de Lyon, Bât. 502, F-69621 Villeurbanne Cedex, France \\ ${ }^{2}$ LPCS, UMR CNRS 5531, ENSERG, BP 257, F-38016 Grenoble Cedex, France \\ ${ }^{3}$ CNDRI, INSA de Lyon, Bât. 303, F-69621 Villeurbanne Cedex, France \\ ${ }^{4}$ CEGELY-ECPA, UPRESA CNRS 5005, INSA de Lyon, Bât. 401, F-69621 Villeurbanne Cedex, France \\ ${ }^{5}$ ESRF, BP 220, F-38043 Grenoble Cedex, France
}

\begin{abstract}
Spatially-resolved total-dose degradation has been performed in MOS transistors by focusing X-ray synchrotron radiation on the gate electrode with micrometer resolution. The influence of the resulting permanent degradation on device electrical properties has been analyzed using current-voltage and charge pumping measurements, in concert with optical characterization (photon emission) and quasi-breakdown measurements.
\end{abstract}

\section{INTRODUCTION}

Silicon metal-oxide-semiconductor (MOS) devices placed into a radiation environment are subjected to rapid degradation of their performances due to total-dose effects induced by ionizing radiation. From the electrical point of view, a wide variety of radiation-induced point defects has been identified to be active in the $\mathrm{Si} / \mathrm{SiO}_{2}$ system $[1,2]$. These defects can act as a parasitic charge in the active area of a MOS device and their electrostatic influence can depend on their location in the structure. It is thus essential to quantitatively study the radiation effects together with their site dependence, especially in MOS field-effect transistors for which an elcctrically-active defect may have not the same importance if it is located in the central part of the gate electrode, on the edge of the transistor channel or near the insulating field-oxide $[3,4]$.

Over the past several years, only a few works have experimentally verified the impact of localized total-dose degradation in MOS devices [5]. They classically used ion beams to locally induce total-dose effects. The aim of this work is to investigate a new experimental approach based on the use of a X-ray focused micro-beam to irradiate at the micrometer scale the active area of a single MOS transistor and to study the electrical response of generated defects as a function of their precise location in the sample. This paper reports the first experimental results obtained on large area MOS transistors, characterized in situ by combining charge pumping (CP) measurements with total-dose micro-irradiation using a focused X-ray beam at micrometer scale.

\footnotetext{
${ }^{\dagger}$ This work has been partially supported by ESRF (Experiment \#HE-443) and by a special INSA grant for multi-laboratory research programs (BQR INSA).

"Corresponding author. E-mail : autran@radecs.org
}
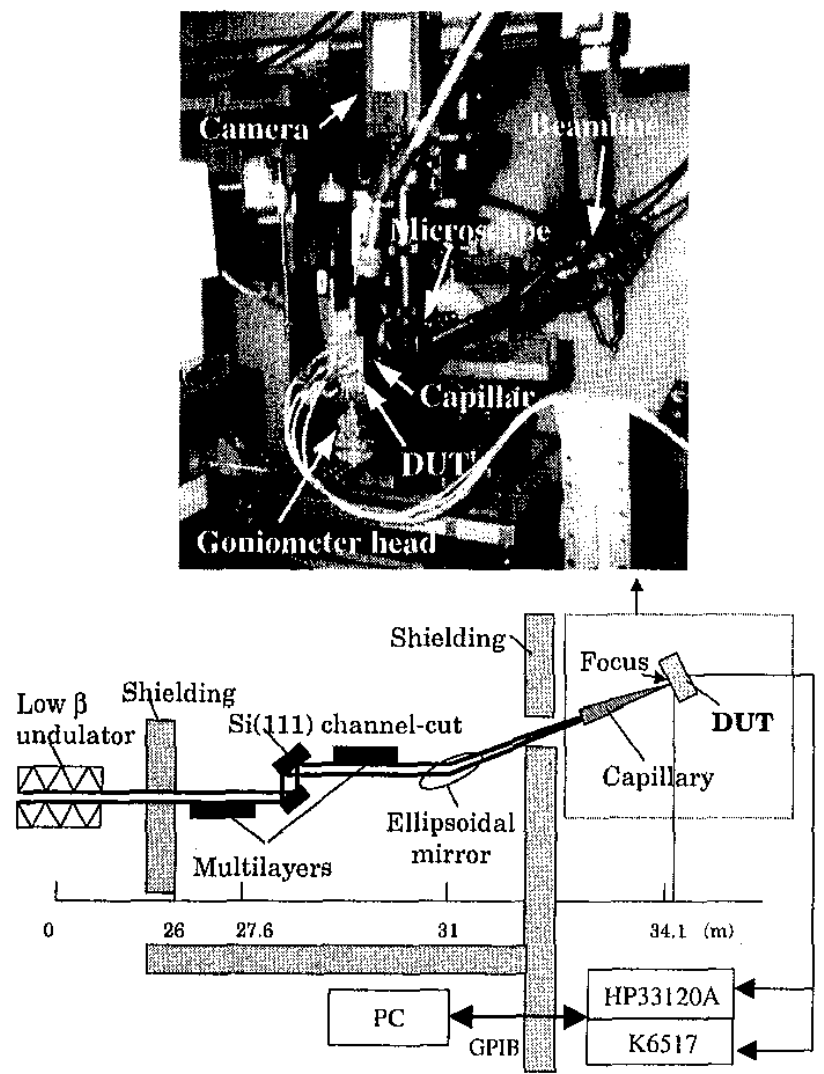

Figure 1. Experimental setup developed at the microfocus beamline (ID13) of the European Synchrotron Radiation Facility (ESRF).

\section{EXPERIMENTAL DETAILS}

\section{A. The Microfocus Beamline}

Synchrotron radiation experiments were performed at the microfocus beamline (ID13) of the European Synchrotron Radiation Facility (ESRF) [6]. The experimental setup is shown in Fig. 1. A monochromatic X-ray beam of $13 \mathrm{keV}$ with a flux of $\sim 6 \times 10^{8}$ photons $\mathrm{s}^{-1} . \mu \mathrm{m}^{-2}$ at $200 \mathrm{~mA}$ ring current was obtained by a combination of a $\mathrm{Si}(111)$ monochromator, ellipsoidal mirror, and tapered glass capillary [7].

A previous study [8] has determined the beam size to be $\sim 2$ $\mu \mathrm{m}$ in diameter at the capillary exit by scanning a knife edge into the beam and recording the intensity with a photodiode. 


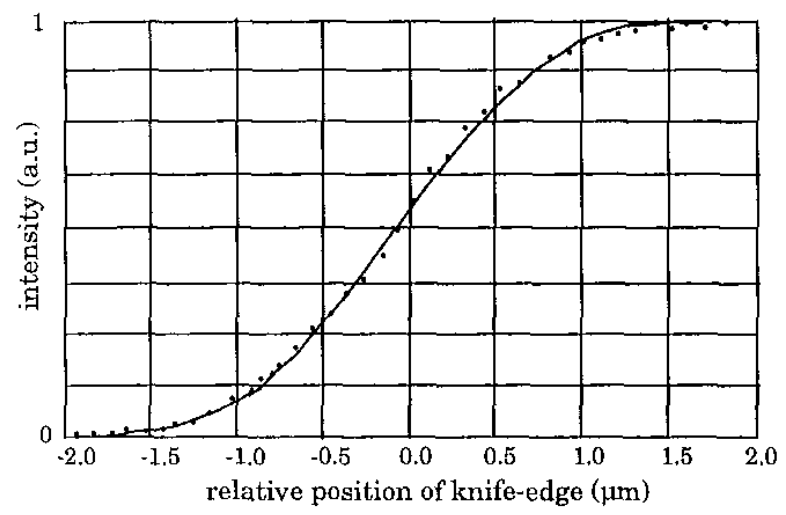

Figure 2. Determination of the beam profile by scanning a knife edge through the beam. Intensity is scalcd to 1 for the knife edge out of the beam. The full line corresponds to a theoretical fit. After P. Engström (reported by Riekcl et al. in Ref. [8]),

Figure 2 shows the experimental relative intensity of the beam as a function of the position of the knife edge and the theoretical curve considering the beam spot as a $2 \mu \mathrm{m}$ diameter disk with rounded edges. Due to the distance of the sample from the capillary exit, the beam size at the sample position was estimated to be $\sim 3 \mu \mathrm{m}$ in our case.

\section{B. Devices and irradiation}

The devices used in this study were large area $\left(100 \times 100 \mu \mathrm{m}^{2}\right) \mathrm{n}$-channel transistors manufactured using a $0.25 \mu \mathrm{m}$ standard CMOS technology with $4.5 \mathrm{~nm}$ gate oxide thickness and $\mathrm{n}^{+}$-type polysilicon gate. They were mounted in Dill 6 ccramic packages. The device under test was fixed on a goniometer head which can be translated along the three directions with an absolute accuracy of $\leq 1 \mu \mathrm{m}$ (Fig. 3). It was connected to the apparatus via short connection coaxial cables.

To determine the beamstop position with respect to the device surface, we used a long distance control microscope and a special alignment sample consisting of a Kevlar fiber cross mounted instead of the device. The cross was aligned in the X-ray beam by watching the appearance of the diffraction pattern on a large area detector placed behind the sample.

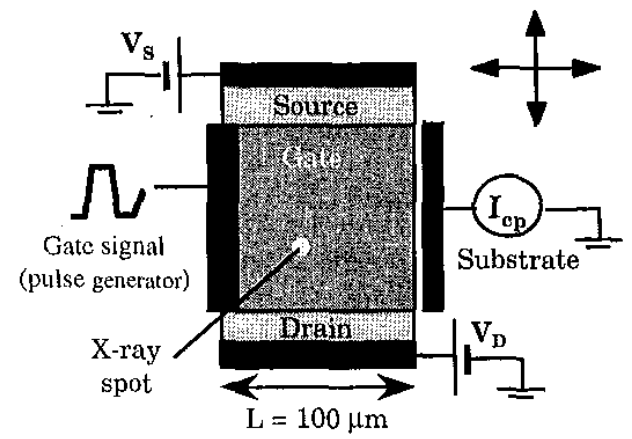

Figure 3. Schematic top view of the device under test (DUT). Motorization of the sample is indicated by arrows. The electrical setup is also schematically represented.
Devices were irradiated at room tempcrature under $+1 \mathrm{~V}$ gate bias (source, drain and substrate grounded) and with a dose rate of $\sim 180 \mathrm{Mrad}(\mathrm{Si}) / \mathrm{s}$ [9]. Note that this last value is due to the extreme luminosity of the ESRF X-ray source. Finally, a fast shutter was used to control the irradiation time with a minimum cxposure of $\sim 2 \mathrm{~ms}$.

\section{RESULTS AND DISCUSSION}

\section{A. Single spot irradiation}

We first consider a MOS transistor submitted to a single spot irradiation. A schematic top view of the transistor gate area is shown in Fig. 4 : the spot (labeled A) is located in the middle of the gate and corresponds to a total dose of $\sim 32 \mathrm{Grad}(\mathrm{Si})$ under conditions previously described.

Fig. 5 shows the charge pumping response of the transistor before and after the spot $\mathrm{A}$. The plateau of the characteristics is directly proportional to the number of interface traps at the $\mathrm{Si} / \mathrm{SiO}_{2}$ interface whereas the edges of these bell-shaped curves are linked to the local surface potential - gate voltage relationship for the electrically active traps $[10,11]$.

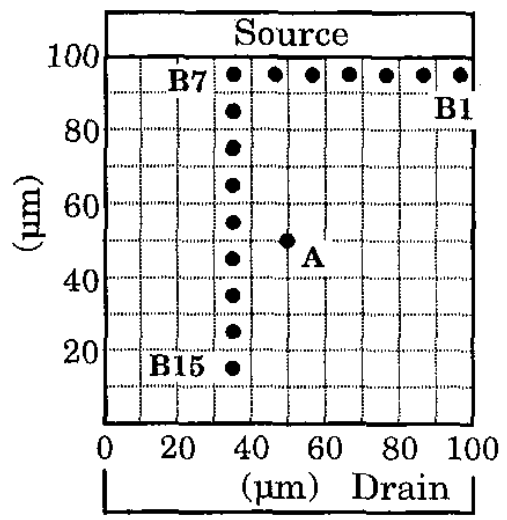

Figure 4. Mapping of the irradiation performed on the transistor gate using the focused micro-bcam. Spot A and spots BI to B15 respectively refer to two distinct devices.

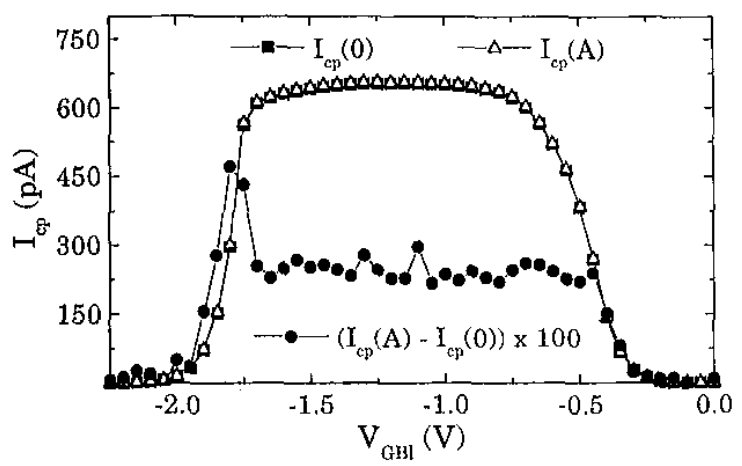

Figure 5. Charge pumping current $\left(\mathrm{I}_{\mathrm{cp}}\right)$ as a function of base level of gate pulses $\left(\mathrm{V}_{\mathrm{GBI}}\right)$ before $(0)$ and after $(\mathrm{A})$ spot $\mathrm{A}$. Measurement conditions : sinusoidal pulses, amplitude $2 \mathrm{~V}$, frequency $5 \mathrm{kHz}$. 


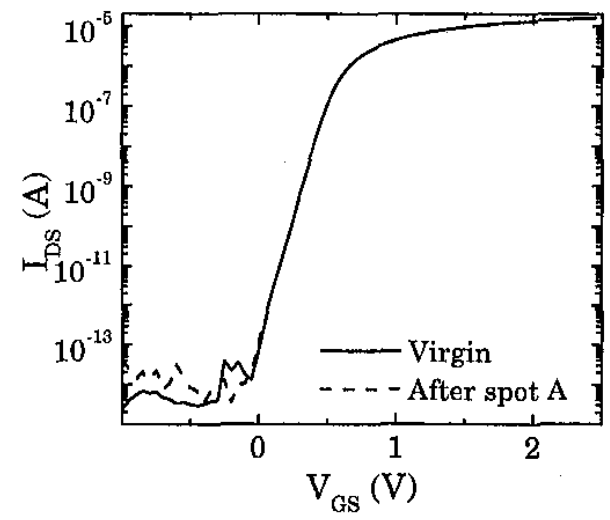

Figure 6. Source-to-drain current $\left(\mathrm{I}_{\mathrm{DS}}\right)$ versus gate-to-source voltage $\left(V_{G S}\right)$ characteristics for a transistor before and after single spot irradiation $(\operatorname{spot} \mathrm{A})$.

After spot A and by substracting the two curves, an increase of $\sim 2.4 \mathrm{pA}$ in the charge pumping current is evidenced, which corresponds to the net creation of $\sim 3000$ active traps. These traps are created on a part of the interface which corresponds to the spot size, i.e., $~ 3.1 \mu \mathrm{m}^{2}$. Consequently, the spot induces an increase of the interface state density of $\sim 9.6 \times 10^{10} \mathrm{~cm}^{-2}$. Considering now the part of the silicon bandgap $\left[\mathrm{E}_{\mathrm{em}, \mathrm{h}}, \mathrm{E}_{\mathrm{em}, \mathrm{e}}\right]$ in which interface traps have been involved in the $\mathrm{CP}$ processes, we obtain for a sinusoidal gate signal $[9,11]$ :

$$
\begin{aligned}
& E_{e m, h}-E_{e m, e}=2 k T \ln \left[\frac{\sigma_{n p} v_{t h} n_{i}}{\ln (2)} \frac{Z}{2 \pi F_{P}}\right] \\
& Z=\sin ^{-1}\left(\frac{2\left|V_{F B}-V_{0}\right|}{V_{G B h}-V_{G B l}}\right)+\sin ^{-1}\left(\frac{2\left|V_{0}-V_{t h}\right|}{V_{G B h}-V_{G B l}}\right)
\end{aligned}
$$

where $\mathrm{T}$ is the temperature, $\mathrm{k}$ is the Boltzmann constant, $\sigma_{n p}$ is the average value of interface trap capture cross sections (separately determined [10]), $\mathrm{v}_{\mathrm{th}}$ is the carrier thermal velocity, $n_{i}$ is the intrinsic carrier density, $F_{p}, V_{0}$ and $\Delta V_{G B}$ are the frequency, the average value and the amplitude of the gate signal respectively, $V_{F B}$ and $V_{\text {th }}$ are the flat-band and threshold voltage of the transistor under test.

From Fig. 5, the central part of the plateau corresponds to $\mathrm{V}_{\mathrm{GBl}} \sim-1.25 \mathrm{~V}$, which leads to $\mathrm{Z}=1.67$ and $\left|\mathrm{E}_{\mathrm{em}, \mathrm{h}}-\mathrm{E}_{\mathrm{em}, \mathrm{e}}\right|=$ $0.342 \mathrm{eV}\left(\sigma_{\mathrm{np}} \approx 10^{-16} \mathrm{~cm}^{2}\right)$. The interface state density at the level of the irradiated zone is thus equal to $D_{i t}=2.8 \times 10^{11}$ $\mathrm{eV}^{-1} \mathrm{~cm}^{-2}$. This level of density is rather moderated if we consider the total deposited dose of $\sim 32 \mathrm{Grad}(\mathrm{Si})$. But the combination of an ultra-thin gate oxide, a rather low gate voltage and a gigantic dose rate could explain such a result.

The impact of this single spot irradiation on the $\mathrm{I}_{\mathrm{DS}}\left(\mathrm{V}_{\mathrm{GS}}\right)$ characteristic of the transistor has been also investigated. Fig. 6 shows that the radiation-induced increase of $D_{\text {it }}$ on a very small area in the transistor channel does not modify the global response of the device. This illustrates the extremely high sensitivity of the $\mathrm{CP}$ technique with respect to standard $\mathrm{I}_{\mathrm{DS}}\left(\mathrm{V}_{\mathrm{GS}}\right)$ measurement for probing a small and spatially located increase of interface traps.

\section{B. Multiple spot irradiation}

We now consider a new device submitted to a series of 15 spots, labeled B1 to B15 in Fig. 4. These spots are distributed along the source side (B1 to B7) and along the transistor channel (B8 to B15). In the same way, Fig, 7 shows the increase of the maximum charge pumping current as a function of cumulative degradation caused by series of spots B1 to B 15 on a transistor initially virgin. Although the CP signal is low, the step-by-step increase is approximately proportional to the number of spots when varying the spot position, excepted near the transistor drain.

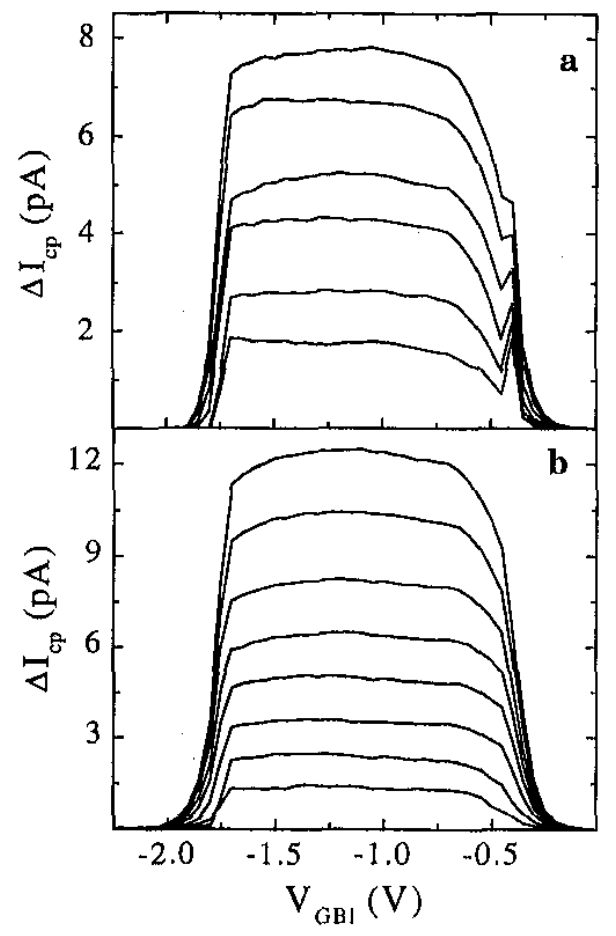

Figure 7. Cumulative increase of the charge pumping current as a function of base level of gate pulses $\left(\mathrm{V}_{\mathrm{GB}}\right)$ before and after spots $\mathrm{B} 1$ to B7 (a), before and after spots B8 to B15 (b). Measurement conditions : sinusoidal pulses, amplitude $2 \mathrm{~V}$, frequency $5 \mathrm{kHz}$.

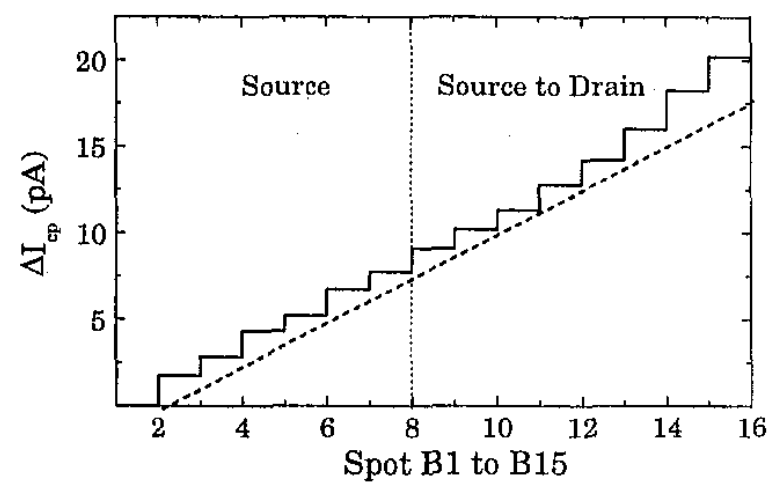

Figure 8. Cumulative increase of the charge pumping current as a function of total-dose irradiation caused by spots B2 to B15 on a transistor initially virgin (see spot positions in Fig. 4). The CP conditions are : sinusoidal signal, amplitude $2 \mathrm{~V}$, frequency $5 \mathrm{kHz}$. 
It results that each irradiation of $\sim 32 \mathrm{Grad}(\mathrm{Si})$ leads to a local increase of $D_{i t}$ of $\sim 2.6 \times 10^{11} \mathrm{eV}^{-1} \mathrm{~cm}^{-2}$. The more pronounced increase near the drain may be due to modifications of the $V_{t h}$ and the $V_{F B}$ profiles in this region of the transistor channel, probably resulting from a slight change in the channel impurity profile. But it can be noticed that the position of spot $\mathrm{B} 15$ is $\sim 10-15 \mu \mathrm{m}$ far from the drain junction which is much more longer than typical doping profile fluctuations near a metallurgical junction [11]. Even if such a position is subject to an error of $\sim 8 \mu \mathrm{m}$ at the end of the irradiation pattern due to experimental constraints (cumulated position crror), this could not reasonably explain the deviation from linearity of the characteristic of Fig. 8.

During the experiments, other single and multiple spot exposures were performed on virgin devices. We did not observe any particular influence of the spot position, i.e., significant differences in $\Delta \mathrm{I}_{\mathrm{cp}}$ when irradiating devices in the central part of the gate or near the source or drain junctions. In fact, a carefully data analysis shows that two identical spot irradiations performed on a virgin interface do not exactly induce the same $\Delta \mathrm{I}_{\mathrm{cp}}$. In other terms, $\Delta \mathrm{I}_{\mathrm{cp}}$ should follow a cerlain (unknown) distribution function that results from experimental incertitude and/or from slight fluctuations in the total-dose response of the $\mathrm{Si}-\mathrm{SiO}_{2}$ interface.

\section{Correlation with photon emission and quasi- breakdown measurements}

The impact of local irradiation on the gate oxide quasibreakdown and breakdown under high electric-field has been investigated by performing emission spectroscopy measurements after irradiation. The experimental setup combined an optical microscope and a Hamamatsu dual mode cooled CCD camera C4880-06. Irradiated devices were submitted to a constant stress voltage of $+7 \mathrm{~V}$ applied to the gate (source, drain and substrate grounded). Photon emission signal was integrated in time over the range $400-1000 \mathrm{~nm}$, while the gate-to-substrate leakage current was simultancously recorded using a HP4155B.

Fig. 9 shows the emission map of the transistor submitted to irradiations B1 to B15 (negative contrast). The electrical response of the same device during the measurement is shown in Fig. 10. Light spots labeled 1,2 and 3 in Fig. 9 simultaneously appear with the gate current steps referenced 1 , 2 and 3 in Fig. 10. They are characteristic of a quasibreakdown phenomenon whereas the intense light spot \#4 is associated to the final film breakdown (not shown on Fig. 10) [13]. From these two figures, it is clear that our experiment reveals no clear topological correlation between the irradiated zone and the zone where occurs the oxide quasi-breakdown or breakdown. In this sense, we can only say the radiation does not enhance breakdown because the two zones do not correspond. Indeed, we can suppose that if we irradiate the component at the same place where breakdown will occur, breakdown will be enhanced in this case.

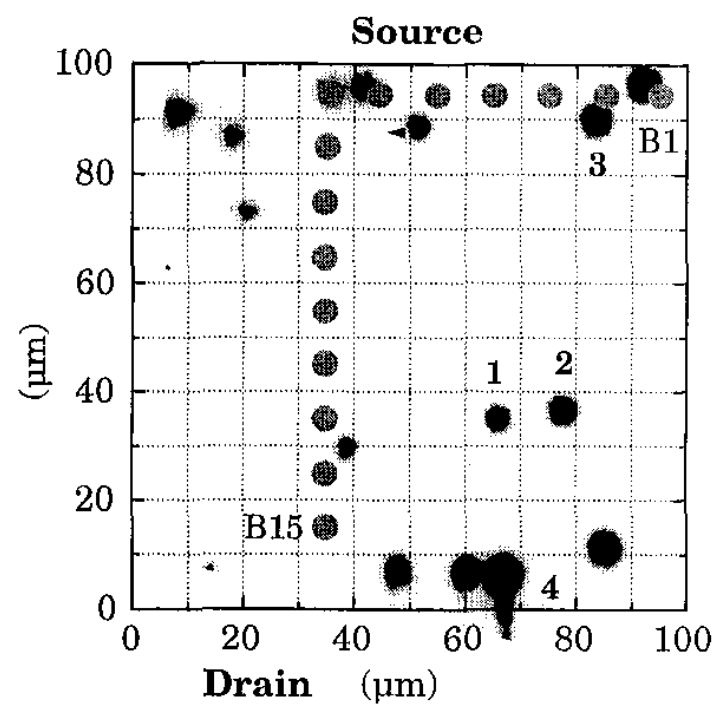

Figure 9. Photon emission image (top view, negative contrast) of the transistor submitted to spots Bl to B15. The photon emission is observed in the range $400-1000 \mathrm{~nm}$ when applying $+7 \mathrm{~V}$ under the transistor gate. The positions of irradiation spots ate also superimposed (gray circles).

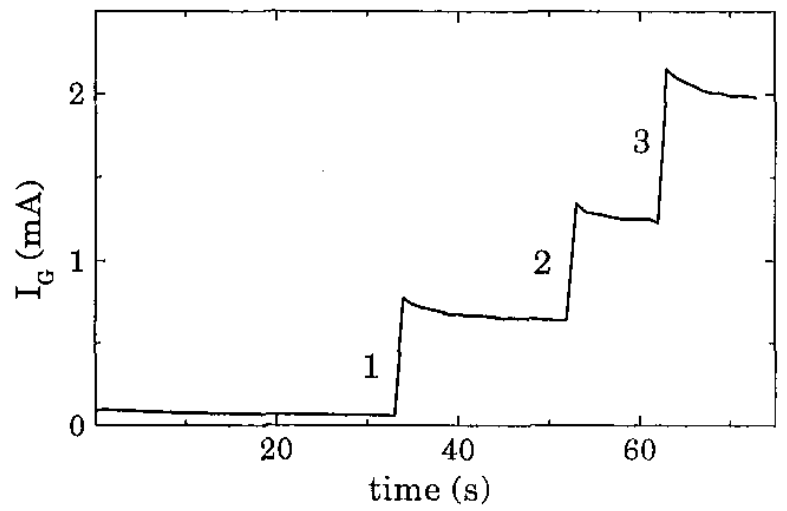

Figure 10. Electrical breakdown observation of the gate oxide of the transistor submitted to spots B1 to B15. The gate-to-substrate current voltage is simultaneously recorded with photon emission data collection shown in Fig. 10.

This experiment has been successfully repeated for different irradiation spot patterns, as illustrated in Fig. 11. Results suggest that the radiation-induced defects may not play significant role in the oxide quasi-breakdown and breakdown phenomenon. But it is important to consider these results with respect to the local defect density induced by irradiation in the particular case of our experiments. Indeed, it has been shown in a previous work [14] that a critical defect density of $\sim 5 \times 10^{13}$ $\mathrm{cm}^{-2}$ for an oxide layer of $4.5 \mathrm{~nm}$ thick should be reached to induce a breakdown path through the oxide. Although it is difficult to estimate the exact number of oxide defects created during a spot irradiation (we only know the fast interface trap density), the trap density can be considered for a thermal oxide to be lower in the oxide bulk than at the interface [3]. For each spot irradiation, the oxide trap density (in the range of 


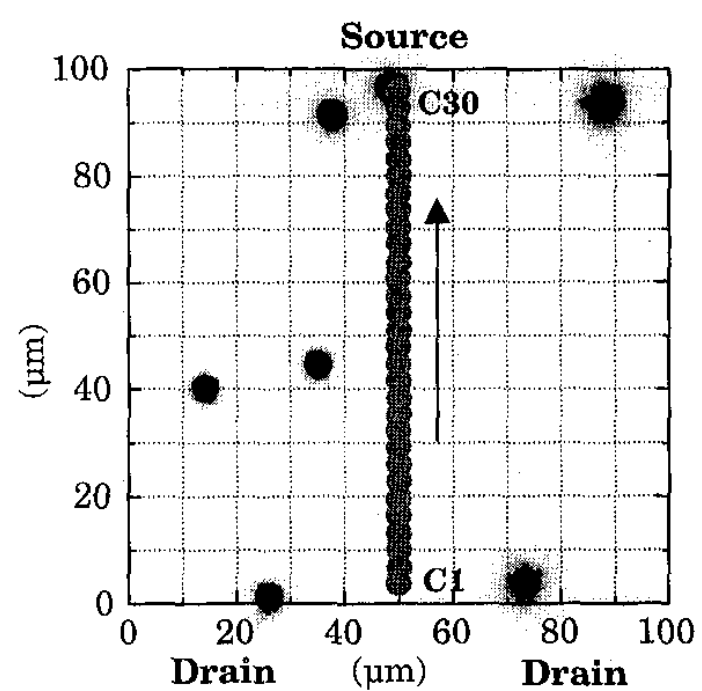

Figure 11. Photon emission image (top view, negative contrast) of the transistor submitted to spots $\mathrm{C} 1$ to $\mathrm{C} 30$ (gray circles).

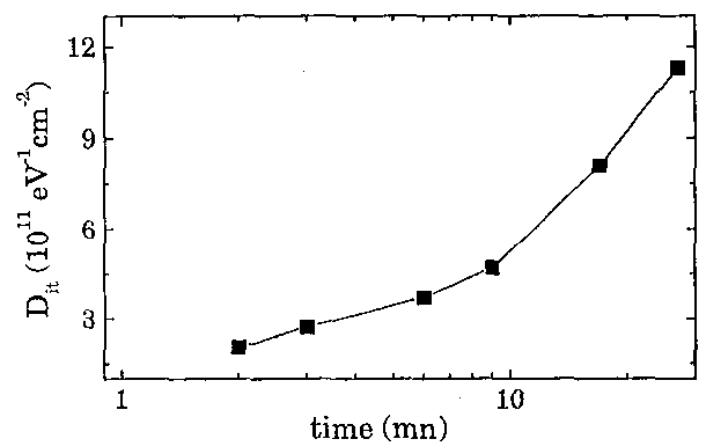

Figure 12. Evolution of the local interface state density as a function of irradiation time at the level of a single spot centered on the transistor gate (spot D, see Fig. 13).

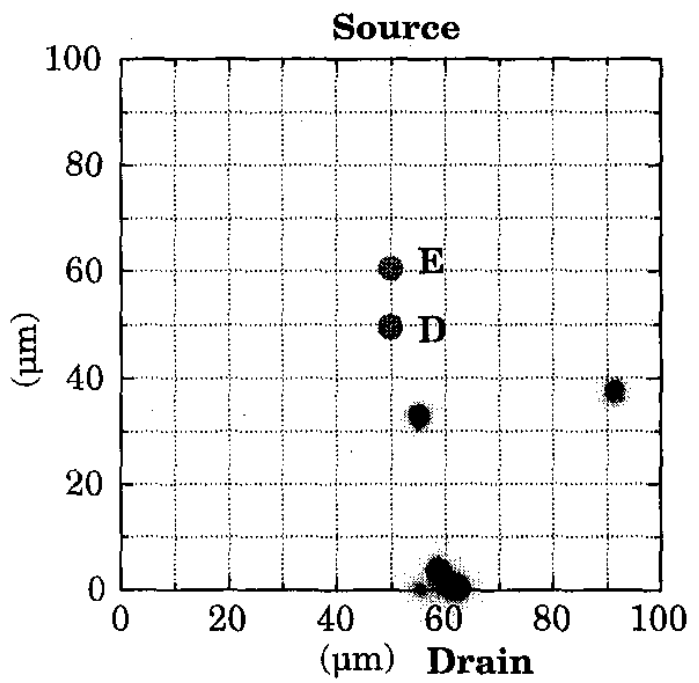

Figure 13. Photon emission image (top view, negative contrast) of the transistor submitted to spots $\mathrm{D}$ and $\mathrm{E}$ (gray circles). Each spot represents $27 \mathrm{~min}$. of irradiation under $\mathrm{V}_{\mathrm{G}}=+1 \mathrm{~V}$. $\left.10^{11} \mathrm{~cm}^{-2}\right)$ is thus very far from this critical density. One more time, we can invoke the extreme dose rate used and the oxide thickness to explain the dramatically weak efficiency of defect creation during irradiation.

In order to increase the radiation-induced defect densities at the interface and also in the oxide bulk, we pushed the irradiation time to a few tens of minutes. Fig. 12 shows the evolution of the local interface state density as a function of irradiation time at the level of a single spot centered on the transistor gate (spot $D, x=y=50 \mu \mathrm{m}$, see Fig. 13). The $D_{i t}$ level of the virgin device is $\sim 2.3 \times 10^{10} \mathrm{eV}^{-1} \mathrm{~cm}^{-2}$. After $27 \mathrm{~min}$. of irradiation under $V_{\mathrm{G}}=+1 \mathrm{~V}$, this level reaches $\sim 1.1 \times 10^{12} \mathrm{eV}^{-1} \mathrm{~cm}^{-2}$. Duc to machine constraint, it was not possible to increase the exposure time and thus the defect density above this value. Nevertheless, on a practical point of view, such a level of density classically corresponds to a worst case for the MOS transistor in terms of interface quality [15].

Fig. 13 confirms the behavior evidenced in Fig. 9 and 11 at a higher defect density level: no correlation exists between irradiation and quasi-breakdown. This result has a dircet and important consequence : even if the defect density is locally multiplied by a factor of $\sim 100$ after irradiation, the quasibreakdown phenomenon may be controlled by other characteristics of the oxide, such as the oxide growth conditions or the roughness at the interface for example [13]. Moreover, this experimental result seems to not agrec with the breakdown percolation model [14] which assumes the gradual formation of a breakdown path during the electrical stress. According to this model, the critical defect density should be preferentially reached in the spot region where pre-cxisting traps have been massively induced by irradiation (by a factor of $\sim 100$ in the present case). Finally, our results confirm the local character of the quasi-breakdown and the fact that it may be not at the origin of the final oxide breakdown [13].

\section{CONCLUSION}

In summary, we have experimented a new radiation-test facility at ESRF for the irradiation of MOS components using a $13 \mathrm{keV}$ x-ray beam of micrometer scale. Our first experimental results demonstrate the feasibility to irradiate large area transistors with a given irradiation pattern. The control of the beam is therefore subjected to improvement in order to be able to perform irradiation with a better spatial accuracy, typically of $\sim 0.1 \mu \mathrm{m}$. In the future, micro-irradiation experiments should also address smaller devices to significantly increase the ratio irradiated area/total gate area.

On the electrical point of view, the effect of local irradiation has been quantified by charge pumping measurements and its impact on the quasi-breakdown and the breakdown of the oxide has been also investigated through the combined analysis of current-voltage measurements and photon emission. For $4.5 \mathrm{~nm}$ thick thermal oxide, our results show that the exact origin of the quasi-breakdown remains unclear and may not be considered as a direct consequence of 
irradiation. New investigations will be necessary to support this hypothesis.

\section{ACKNOWLEDGMENTS}

The authors gratefully thank P. Girard (INSA/LPM), P. Duvauchelle, E. Cendre (INSA/CNDRI), C. Banc (ENSERG/LPCS) and the ID-13 beamline technical staff (ESRF, Grenoble) for their assistance and support.

Part of this work was done in the frame of the new established Centre de Projets en Microélectronique Avancée (CPMA), Grenoble, France. CPMA is a multiprogram laboratory operated by the Commissariat à l'Energie Atomique (CEA), the Centre National de la Recherche Scientifique (CNRS), the Institut National Polytechnique de Grenoble (INPG) and the Institut National des Sciences Appliquées de Lyon (INSA).

\section{REFERENCES}

[1] N.M. Johnson, "Electronic and optical properties of silicon dangling-bond defects at the $\mathrm{Si}_{-} \mathrm{SiO}_{2}$ interface," in The physics and chemistry of $\mathrm{SiO}_{2}$ and the $\mathrm{Si}_{-} \mathrm{SiO}_{2}$ interface, edited by C.R. Helms and B.E. Deal (Plenum Press, NewYork, 1988), pp. 319-326.

[2] R.E. Stahlbush, "Slow and fast state formation caused by hydrogen", in The physics and chemistry of $\mathrm{SiO}_{2}$ and the $\mathrm{Si}_{-} \mathrm{SiO}_{2}$ interface - 3, edited by H.Z. Massoud, E.H. Poindexter and C.R. Helms, (The Electrochemical Society; Pennington, 1996), pp. 525-537.

[3] O. Flament, J.L. Autran, O. Musseau, P. Roche, O, Faynot and $\mathrm{R}$. Truche, "Charge pumping analysis of radiation effects in LOCOS parasitic transistors," IEEE Trans. Nucl. Sci. 44, 1930 (1997).

[4] S. Picrunck, J.L .Autran, B. Leroy and B. Balland, "Location of individual traps in DRAM cell transistors by charge pumping technique," Microclec. Eng. 36, 83 (1997).

[5] M. Koh, B. Shigeta, K. Igarashi, T. Matsukawa, T. Tanii,
S. Mori and I. Ohdomari, "Quantitative analysis of induced $\mathrm{Si} / \mathrm{SiO}_{2}$ interface defects by means of $\mathrm{MeV} \mathrm{He}$ single ion irradiation," Appl. Phys. Lett. 68, 1552 (1996). See also references therein.

[6] P. Engstrom, S. Larsson, A. Rindby, "A submicron synchrotron X-ray beam gencrated by capillary optics," Nucl. Instrum. Meth. Phys. Res. A302, 547 (1991).

[7] P. Engström, S. Fiedler and C. Riekel, "Microdiffraction instrumentation and experiments on the microfocus beamline at the ESRF," Rev. Sci. Instrum. 66, 1348 (1995).

[8] C. Riekel, A. Cedola, F. Heidelbach and K. Wagner, "Microdiffraction experiments on single polymeric fibers by synchrotron radiation," Macromolecules 30, 1033 (1997).

[9] D.E. Cullen, J.H. Hubbel and I. Kissel, EPDL97 The Evaluated Data Library, UCRL-ID-50400, $\underline{6} \operatorname{Rev} 5$ (1997).

[10] J.L. Autran and C. Chabrerie, "Use of the charge pumping method with a sinusoidal gate waveform", SolidState Electronics," Solid-State Electron. 39, 1394 (1994).

11] P. Heremans, J. Witters, G. Groeseneken and H.E. Maes, "Analysis of the charge pumping technique and its application for the evaluation of MOSFET degradation," IEEE Trans. Electron Devices 36, 1318 (1989).

[12] P. Masson, G. Ghibaudo and J.L. Autran, "An improved time domain analysis of the charge pumping current," IEEE Trans, Electron Devices, submitted.

[13] O. Brière, A. Halimaoui and G. Ghibaudo, "Brcakdown characteristics of ultra-thin gate oxides following field and temperature stresses," Solid-State Electron. 41, 981 (1997).

[14] R. Degraeve, P. Roussel, G. Groeseneken and H.E. Maes, "A new analytic model for the description of the intrinsic oxide breakdown statistics of ultra-thin oxides," Microelectron Reliab. 36, 1639 (1996).

[15] J.L. Autran, C. Chabrerie, O. Flament, P. Paillet, J.L. Leray, J.C. Boudenot, "Radiation-induced interface traps in hardened MOS transistors : an improved charge-pumping study", IEEE Trans. Nucl. Sci 43, 2547 (1996). 